\section{GAS DISCHARGES REJUVENATED}

\section{Plasma Physics}

By J. G. Linhart. (Series in Physics.) Pp. xi +278. (Amsterdam : North-Holland Publishing Company New York: Interscience Publishers, Inc., 1960.) $50 s$.

\section{Basic Data of Plasma Physics}

By Prof. Sanborn C. Brown. (Technology Press Books in Science and Engineering.) Pp. viii +336 . (Cambridge, Mass.: The Technology Press of the Massachusetts Institute of Technology ; New York: John Wiley and Sons, Inc. ; London : Chapman and Hall, Ltd., 1959.) 52s. net.

HERF cannot be many examples in the history of physics of an almost moribund branch reviving and blossoming with such vigour as happened in the past ten years to what used to be called 'conduction of electricity through gases' or 'electric gas discharges'. The resurrected seience is ealled 'plasma physics', adopting the name which Irving Langmuir gave almost forty years ago to the tough 'substance' of gas discharges, the highly ionized, highly conducting gas. The revival was due in the first place to the hope of controlled fusion, and led in a few years to giant devices such as Zeta, Stellarator and Ogra which dwarfed not only the modest discharge tubes in which J. J. Thomson and Langmuir made their classical discoveries, but also the largest rectifiers ever made for power stations. It is now common knowledge how successful the plasma was in repelling these first attempts for heating it up to millions of degrees, how it managed to dissipate the energy by processes nobody had thought of. This led to a general sobering and a determination to study the plasma before trying to force it to do what it so evidently dislikes doing. 'Thero may be some legitimate doubt whether it will be ever possible to 'study the plasma' except by feeding energy into it in special configurations of electromagnetic fields, and whether such knowledge will ever add up to a general mastery; but the intention is certainly laudable.

It can be said with confidence that at the present there exists no better introduction to this complex subject than Dr. Linhart's book. The author has the three rare qualifications of experience, mathematical facility and inventive imagination. He also possesses didactic ability, but this will be appreciated only by those readers who share with him the advantages of mathematical ability and of an active mind. It is not a book which can be imbibed passively, or uncritically.

'The first three chapters on motion of electrons and ions, fluid description of plasmas and equilibrium configurations aro more or less conventional and will make fairly easy reading for postgraduate physicists. The author comes into his own in the far more difficult chapters on waves and instabilities, shock waves and relaxation processes. Unfortunately, the derivation of the Fokker-Planck equation is almost incomprehensible, which is particularly regrettablo in a subject in which Einstoin and Debye have created masterpiecos of simple exposition. 'This, however, is a rare exception in Linhart's book. The final chapters on rosearch on controlled fusion and other applications, though perhaps somewhat too brief, make excellent reading.

Prof. Sanborn Brown's book on "Basic Data of Plasma Physies" is not only an excellent text-book on the more orthodox chaptors of gas discharges, but also a reference book which one cannot afford not to have on the sholf. Many of the most valuable data in his book (on high-frequency breakdown, on diffusion and recombination) are the results of the rescarches of its author and of his collaborator, Manfred Biondi. While much of the material on elementary processes is covered also by Massey and Burhop's "Impact I'henomena", about one-half of the book which deals with breakdown conditions and with discharges is a happy complement to that other excellent work. The arrangement is so clear, with full description of the experimental methods and with all the relevant theory required to explain the data, that, the book can bo equally recommended to the student and to the expert research worker. D. GABOR

\section{HYPERSONIC FLOW PHENOMENA}

\section{Hypersonic Flow Theory}

By Wallace D. Hayes and Ronald F. Probstein. (Applied Mathematics and Mechanics, Vol. 5. Series of Monographs prepared under the auspiecs of the Applied Physies Laboratory, The Johns Hopkins University.) Pp. xiv +464 . (New York: Acadomic Press, Ine. ; London : Academic Press, Ine. (London), Ltd., 1959.) 11.50 dollars.

THIs book will prove invaluable to the increasing number of students and rescarch workers who are becoming interested in hypersonic flow phenomena. Although it is mainly theoretical, it is not such that it requires the reader to have very advanced mathematical knowledge. It should appeal to the engineer who has to tackle the practical problem of hypersonic flight just as much as to the physicist who wishes to acquire a physical understanding of hypersonic flow phenomena. Both authors have over the years made important contributions to hypersonic flow theory and are by experience fully qualified to write authoritatively on this subject, and thus to convey some of the knowledge they have gained in this important. field of research, to interested readers of thoir book. Much of the material presented has not been published elsewhere and reforence is also made to many Russian papers on hypersonic flow problems. Some of these are discussed in detail in the text.

The scope of the book is fairly wide, but it does not include any material on high-temperature gas dynamies and magnetogasdynamics. Throughout the text emphasis is laid on fundamental aspects of hypersonic flow and on the development of a soundly based theory. Semi-empirical theories aro generally avoided except those which contribute in some way to the understanding of hypersonic flow phenomena. 'Theories which are based on wrong assumptions are not discussed though they may give good agreement with experiment.

In more detail, Chapter 1 is devoled to the consideration of the general features of hypersonic flow and some of the basic concepts used in the devolop. ment of the theory. Chapter 2 is concerned with what is referred to as the 'small disturbance theory', as distinct from lincarized theory, in relation to flow past slender bodies and gives similarity rules for determining the flow. Special reference is made to van Dyke, who first used the expression 'small disturbance theory' in his studies of flows in which the disturbances in volocity and pressure are small 